\title{
Predictors of Self-Actualization
}

\author{
MELINDA C. PAUSANOS \\ http://orcid.org/0000-0002-7035-0757 \\ mcpausanos@universityofbohol.edu.ph
}

\begin{abstract}
The Theory on Attaining Self-actualization among Older Adults stated that there are characteristics that a person should develop which will enable him or her to become self-actualized. These characteristics namely emotional intelligence, spirituality and life satisfaction as possible predictors of self-actualization among older adults, were investigated in this study to validate those assumptions of the theory. This descriptive-correlational study utilized a multi-stage sample of 180 senior citizens in Tagbilaran City, Bohol. A 5-part instrument package was utilized to (1) describe the respondents' demographic profile and obtain measures for their (2) emotional intelligence using the 30-item Trait Emotional Intelligence Questionnaire-Short Form (TEIQue-SF), (3) spirituality using the 12-item Functional Assessment of Chronic Illness Therapy-Spiritual Well-Being Scale (FACIT-Sp), (4) life satisfaction using the 5-item Satisfaction with Life Scale (SWLS)and (5) selfactualization using a 16-item questionnaire developed by Boyum (2004). A Pearson $r$ analysis indicated that emotional intelligence $[r(180)=.232$, $p=.004]$, spirituality $[r(180)=.295, p=.019]$, and life satisfaction $[r(180)=.530$, $p=.000$ ] correlate positively with self-actualization. Multiple regression analysis further indicated that the three variables significantly predict selfactualization $(p=.000)$. The findings suggest that becoming a self-actualized older adult requires the combined attributes of having a sense of spirituality, developing emotional intelligence and attaining life satisfaction.
\end{abstract}

Keywords: older adult, senior citizen, Filipino family, life satisfaction, emotional intelligence, spirituality, religion 


\section{INTRODUCTION}

The Theory on Attaining Self-Actualization among Older Adults states that self-actualization of an older adult is attributed to his/her capability as a human being and perspective in life. It is a product of different experiences of a person and can be attained depending on his/her characteristics. Specificall, such characteristics and experiences correspond to factors such as the sense of spirituality, sense of emotional intelligence and life satisfaction. This study aimed to validate the assumptions of the theory on the influence of spirituality, life satisfaction and emotional intelligence on the attainment of self-actualization among older adults.

Emotional intelligence is the foundation of each relationship, and the power of those emotions cannot be overlooked. Emotions often override thoughts and profoundly influence behavior. Most commonly, self-actualizing people see life clearly. They are less emotional and more objective, less likely to allow hopes, fears, or ego defense to distort their observations. Self-actualizing people are dedicated to a cause or vocation for which it is a requirement to grow something greater than oneself and success at one's chosen tasks. It is possible that self-actualization can reflect experiences that have affected a person in a positive way. These experiences can motivate people to pursue and reach their goals (Bailey, Eng, Frisch, \& Snyder, 2007).

Consequently, hope and optimism both consist of cognitive processes that are usually oriented towards reaching one's goals and the perception of those goals. Thus, self-actualization comes from within an individual based on the individual's values and what he or she holds dear. For some it is family, for others it is love, and for others, it is money or other material items; either way, it varies from one person to another. However, expressions of sense of spirituality through religious practice or compassion, service to others or passing on wisdom to succeeding generations often bring deep personal satisfaction, comfort, and peace to older adults and thus help them mature more successfully. "Spirituality" is important in the lives of older adults as they seek to, identify, trust, and invest in meanings, values, and relationships that cannot be lost or taken away by the unexpected changes of the aging process (Petrides, 2009).

Even though older adult Filipinos are also facing the global crisis, they can actively use what they are made of on their way to recovery. These are by winning repeat businesses through hospitality and utmost care by 
the members of the family, by treating each order with respect, by being inspired by their families to work hard. It is important to ensure that the older adult person is making satisfactory progress in his or her day-to-day life even within the hierarchy of needs. According to Bulatao (1989), Filipinos by nature possess a strong sense of resilience. This resiliency accounts for the fact that they can endure life's adversities and can withstand poverty over a long period. Filipinos can still laugh or brush away a tear and can make a humorous comment in the face of a tear-jerker scene. This tenaciousness or resilience is sublimation to self-actualization in the real sense of Maslow's paradigm.

However, older adults' life satisfaction could be explained by the individual's access to key resources - material, social, or personal characteristics that a person possesses, which may be critical in promoting and maintaining well-being, because they help him/her achieve his/her personal goals and fulfil his/her basic physical and psychological needs (Diener \& Fujita, 1995). Among older adults, being married or having a partner is a strong resource for life satisfaction, because it provides companionship and social support (Diener, Suh, Lucas, \& Smith, 1999). Moreover, the inclusion of personality in addition to health, marital status, and financial resources is needed to obtain a more accurate picture of the foundations of older adults' life satisfaction.

In light of the related literature reviewed, the different attributes of an older adult, specifically emotional intelligence, spirituality and life satisfaction correspond to the older adult's fundamental need that prompts them to shift awareness to the existence of a higher need which ultimately leads them to self-fulfillment through self-actualization

\section{PROBLEM AND HYPOTHESES}

The study aimed to validate the assumptions of Attaining SelfActualization among Older Adults. Furthermore, it sought to determine the predictors of self-actualization among older adults in Tagbilaran City, Bohol.

From these assumptions, the following hypotheses were tested:

Ha1. The higher the emotional intelligence, the more self-actualized are the older adults.

Ha2. The higher the spirituality, the more self-actualized are the older adults

Ha3. The higher the life satisfaction, the more self-actualized are the older adults 


\section{METHODOLOGY}

To meet the research objectives, the investigator made use of a descriptive-correlational design to test the study hypotheses.

Employing a multistage sampling technique, 180 older adults from eight selected barangays in Tagbilaran City, Bohol, participated in the study. Those aged 60 to 75 years old were eligible to participate. The only criteria for exclusion would be the presence of significant cognitive and neurosensory deficits

Through several home visits conducted by the researcher and her trained research assistants, respondents were personally invited to participate in the study. Prior to data-gathering, informed consent was sought which involved a thorough verbal and written explanation of the study objectives and allowing time for questions or concerns to be entertained. It was likewise emphasized to the older adults that joining the study is entirely voluntary. They may refuse to answer the questionnaire as they wish and non-participation in the study would not affect them in any way.

Self-report measures were utilized to yield data on the study variables. A five (5) - part research instrument, accomplishable in 30 to 45 minutes, was put together for this purpose. To facilitate comprehension and improve administrability, the entire instrument package was provided with Visayan translations (the respondents' mother tongue). Moreover, contents of the said instrument package included the first part which is a researcher-made questionnaire obtaining the demographic profile of each respondent, while the second through fifth parts are standardized instruments measuring the target constructs of the study.

Specifically, to yield data on the study's predictor variables (or independent variables), the Trait Emotional Intelligence Questionnaire - Short Form (TEIQue-SF), Functional Assessment of Chronic Illness Therapy-Spiritual Well-Being Scale (FACIT-Sp), and Satisfaction with Life Scale (SWLS) were utilized to measure emotional intelligence, spirituality, and life satisfaction, respectively.

The Trait Emotional Intelligence Questionnaire - Short Form (TEIQueSF), developed by Konstantin Vasily Petrides, is a 30-item questionnaire designed to measure global trait emotional intelligence. It is based on the full form of the TEIQue. Two items from each of the 15 distinct facets of the TEIQue (i.e., adaptability, assertiveness, emotional perception) were selected for inclusion, based primarily on their correlations with the corresponding total facet scores (Petrides \& Furnham, 2006). 
The respondents were required to rate each statement on the TEIQueSF on a 7-point Likert scale by putting a circle around the number that best reflects their degree of agreement or disagreement with that statement. There were seven possible responses to each statement ranging from 'Completely Disagree' (number 1) to 'Completely Agree' (number 7) (Petrides, 2009). In the study, scores on each statement were summed up and then interpreted as follows: low (score of 30-89), average (score of 90-150) and high (score of 151-180) in emotional intelligence.

The Functional Assessment of Chronic Illness Therapy-Spiritual WellBeing Scale (FACIT-Sp), developed by Bredle, Salsman, Debb, Arnold, and Cella (2011), is a 12-item questionnaire which uses a 5-point Likert-type scale to measure one's reported spiritual well-being ( $0=$ Not at all; $1=\mathrm{A}$ little bit; 2 = Somewhat; 3 = Quite a bit; and 4 = Very much). Scores on each item were summed. Interpretation and the corresponding range of scores were as follows: very low (0-11), low (12-23), average (24-36), high (37-48) and very high (49-60) in spirituality.

The 5-item Satisfaction with Life Scale (SWLS), developed by Diener, Emmons, Larsen \& Griffin (1985), required the respondents to rate their degree of agreement or disagreement of each statement on a 7-point Likerttype scale $(1$ = strongly disagree, 2 = Disagree, 3 = slightly disagree, $4=$ Neither Agree or disagree, 5 = Slightly agree, $6=$ Agree, $7=$ Strongly agree).

Scores on the SWLS may be interpreted in absolute rather than relative terms. In this case, it has been suggested that a score of 20 is regarded as neutral, while scores over 20 represent satisfaction (21-25=slightly satisfied; $26-30=$ satisfied), and scores of less than 20 represent dissatisfaction (15-19=slightly dissatisfied; 5-9=extremely dissatisfied) (Pavot \& Diener, 1993). The test-retest reliability of the SWLS for a 2-month interval is 0.82 (Diener et al., 1985). In their 1993 review, Pavot and Diener reported testretest reliability ranging $0.83-0.50$ - in a time interval from 2 weeks to 4 years and, in general, higher reliabilities were associated with shorter retest intervals.

On the other hand, measuring the study's criterion variable (or dependent variable), Boyum's (2004) Self-Actualization scale is a 16-item questionnaire, which requires the respondent to rate on a 10-point scale, the extent to which he/she possesses the qualities of a self-actualized person as described in each item (10 being the score reflecting strong agreement to have possessed each quality). Scores in each item were summed and interpreted as: very low (16-46 points), low (47-73), average (74-103), high 
(104-131) and very high (132-160) in self-actualization. The highest score is 160 , and the lowest score is 16 . However, there are no exact cut-off points for interpretation indicated by Boyum (2004). Grouping of scores was thus done arbitrarily in the study, bearing in mind the author's comment that the closer one is to 160 , the more self-actualized he/she is.

The data collected were subsequently analyzed with the aid of the Statistical Package for the Social Sciences (SPSS) version 17 software. They were analyzed using percentage for profiling of respondents. Meanwhile, inferential statistics, specifically Pearson product-moment correlation (Pearson $r$ ) and multiple regression analysis, were used to determine relationships among the study variables, with $p$ values of less than 0.05 considered as statistically significant.

\section{RESULTS AND DISCUSSION}

A total of 180 older adults who met the inclusion criteria participated in the study. Table 8 presents their demographic profile

Table 1 shows an equal number of male and female respondents. The majority were married followed by those who were widowed. The respondents' age ranged from 60 to 75 years old which corresponded to the study's inclusion criteria. They mostly lived in an urban area.

It is notable that all the respondents had attended school, although a majority only completed elementary education. Most of them were not working but received subsidy from their children working in the country or overseas. Other older adults had no work while others received a monthly pension as a benefit from the government or private sector after retirement. Sources of income of some of the respondents included farming, fishing or being employed as drivers or laborers.

Table 1. Respondents' demographic profile

$(\mathrm{N}=180)$

\begin{tabular}{lcc}
\hline \multicolumn{1}{c}{ Demographic Variables } & Frequency & $\%$ \\
\hline Gender & & \\
Male & 90 & 50.0 \\
Female & 90 & 50.0 \\
\hline
\end{tabular}

Civil Status

Single 


\begin{tabular}{lcc}
\hline \multicolumn{1}{c}{ Demographic Variables } & Frequency & $\%$ \\
\hline Widow/Widower & 69 & 38.2 \\
\hline Educational Attainment & 67 & 37.2 \\
$\quad$ Elementary & 50 & 27.8 \\
Secondary & 47 & 26.1 \\
College & 16 & 8.90 \\
Post-Graduate & & \\
\hline Status & 58 & 32.2 \\
Not working, with subsidy & 55 & 36.8 \\
Not working & 46 & 25.6 \\
With pension & 21 & 11.7 \\
Working & & \\
\hline Living with & 93 & 51.7 \\
Children & 67 & 37.2 \\
Spouse & 12 & 6.70 \\
Relatives & 8 & 4.40 \\
Caregiver &
\end{tabular}

Note. Percentage totals may not equal 100 due to rounding.

It can be deduced from the data that although the respondents were predominantly married, a majority still lived with their children, tailed closely by those who were not. This result implied that these married individuals lived together by consensual arrangement, or had married children who did not own any dwelling yet.

Majority of the respondents were receiving a subsidy from their children working locally or overseas. This result implied cohesiveness among Filipino families who served as emotional blankets for the older adults. It was reinforced that although the majority of the respondents were elementary graduates only, this was not a hindrance in supporting their children who landed in jobs locally or overseas. Their effort of investing in their children's education had evidently paid off. Now, it is their children who are supporting them.

Table 2 presents the reported self-actualization, emotional intelligence, spirituality and life satisfaction of the older adult respondents. 
Table 2. Reported self-actualization, emotional intelligence, spirituality and life satisfaction of respondents

$(\mathrm{N}=180)$

\begin{tabular}{llll}
\hline Variables & Mean & Std. Deviation & Interpretation \\
\hline Self-actualization & 121.12 & 27.77 & High \\
\hline Emotional Intelligence & 132.31 & 28.64 & Average \\
\hline Spirituality & 33.65 & 7.83 & Average \\
\hline Life satisfaction & 26.20 & 5.25 & Very Satisfie \\
\hline
\end{tabular}

As shown in Table 2, a majority of the respondents reported a high level of self-actualization. They were generally very satisfied with life. The said findings provided insight that as an individual ages, higher level needs specifically self-actualization needs were achieved. Most individuals who reached old age also possessed a certain degree of contentment with life as a whole. Although older adult Filipino respondents are facing a global crisis, they had the mental or physical ability to do something to be self-actualized by being inspired by their supportive families.

This result is consistent with the views of Cruz (2004) that selfactualization among the Filipino older adult is ably provided for by the ideally and typically close-knit Filipino family. The thought and feeling of being wanted, cared for and useful more than compensates for the poverty they have endured over the past years. So much so, that Filipino older adults can still achieve self-actualization which defies the hierarchy ladder of Maslow (Cruz, 2004).

Furthermore, studies contend that among older adults, being married or having a partner is a strong resource for life satisfaction, because it provides companionship and social support (Diener, Suh, Lucas, \& Smith, 1999; Mroczek \& Spiro, 2005). Thus, with most of the respondents living with their spouse, grandchildren and relatives, they are more satisfied with their lives owing to the consistent social contact and family composition that they regard as sources of happiness.

To determine if a relationship exists between self-actualization and the three independent variables (emotional intelligence, spirituality and life satisfaction), a Pearson product-moment correlation was done. As shown in Table 3 , a slightly significant positive correlation exists between emotional intelligence and self-actualization, $r(180)=.232, p=.004$. The higher the emotional intelligence of the older adult, the more self-actualized he/she is. 
Table 3. Correlates of self-actualization

\begin{tabular}{lccc}
\hline & $\begin{array}{c}\text { Emotional } \\
\text { Intelligence }\end{array}$ & Spirituality & Life Satisfaction \\
\hline Pearson Correlation & .232 & .295 & .530 \\
\hline$p$-value & $.004^{* *}$ & $.019^{*}$ & $.000^{* *}$ \\
\hline
\end{tabular}

Note. $d f=180$

a the $r$ values are presented; all three variables are correlated with selfactualization

${ }^{* *} p<.01,{ }^{*} p<.05$

Self-actualization can be observed in older adults who can level off feelings without inhibitions and effectively manage their emotions. This is consistent with Greenberg's (1983) findings which contends that because of emotional strength, self-actualizing people tend to be less egocentric than non-self-actualizing people; meaning, they are better able to accept others on their own terms. De Lazzari (2002) yielded to the fact the emotional self-control or being in control of one's emotion, and behavior is another important quality for a person, as it helps them create a safe environment loaded with mutual trust and equity.

Table 3 also shows that a significant slightly positive correlation existed between spirituality and self-actualization, $r(180)=.295, p=.019$. The higher the level of spirituality of the older adult, the more selfactualized he/she is. Expressions of spirituality through religious practice or compassion, service to others or passing on wisdom to succeeding generations (generativity) often bring deep personal satisfaction, comfort, and peace to older adults and helps them mature more successfully. Spirituality connects older adults with the profoundly powerful and divine force that is present in this universe. Whether they are looking for worldly success, inner peace, or supreme enlightenment, no knowledge can propel one to achieve his/her goals and provide as effective a plan for living as does spiritual knowledge. Finally, the sense of spirituality is considered a lifelong process, and it can serve for the entire lives, the basis for self-care is the foundation for long-lasting satisfaction, happiness in life and self-actualization, which are intricately linked to mental, emotional, and physical health (Bandura, 1999). 
Lastly, Table 3 shows that a significant moderately positive correlation exists between life satisfaction and self-actualization, $r(180)=.530, p=.000$. The more satisfied, the older adult is with his/her life, the more self-actualized he/she is. The life of older adult respondents had been productive; their conditions strengthened their faith and spiritual beliefs. It can be surmised that older adults, due to their age and experiences, possess life satisfaction and have attained spiritual development. The positive feelings of older adults create an emotional space that allows him/her to utilize creativity to not only enjoy life more but also reserve something on emotional and life resources that help whenever they face the adversity.

The preceding analyses rejected the three null hypotheses. Therefore, linearly, emotional intelligence, spirituality and life satisfaction of older adult respondents all have a bearing on self-actualization. A multiple regression analysis was conducted to evaluate how well emotional intelligence, spirituality and life satisfaction predicted self-actualization. Table 4 shows the regression model summary.

Table 4. Regression model summary for predictors of self-actualization

\begin{tabular}{|c|c|c|c|c|c|c|c|c|}
\hline \multirow{2}{*}{$R$} & \multirow{2}{*}{$R^{2}$} & \multirow{2}{*}{ Adjusted $R^{2}$} & \multirow{2}{*}{ SEM } & \multicolumn{5}{|c|}{ Change Statistics } \\
\hline & & & & $\mathrm{R}^{2}$ Change & F Change & df1 & $\mathrm{df} 2$ & $p$-value \\
\hline .577 & .333 & .321 & 22.88 & .333 & 29.227 & 3 & 176 & $.000^{* *}$ \\
\hline
\end{tabular}

Note. SEM=Standard Error of the Estimate ${ }^{* *} p<.01$

As shown in Table 4, the linear combination of emotional intelligence, spirituality and life satisfaction was significantly related to self-actualization. Furthermore, 33.3 percent of the variance of self-actualization (the dependent variable) is contributed by emotional intelligence, spirituality and life satisfaction (the independent or predictor variables). 
Table 5. Regression coefficients for predictors of self-sctualization

\begin{tabular}{|c|c|c|c|c|c|}
\hline \multirow{2}{*}{$\begin{array}{l}\text { Independent } \\
\text { Variables }\end{array}$} & \multicolumn{2}{|c|}{$\begin{array}{l}\text { Unstandardized } \\
\text { Coefficients }\end{array}$} & \multirow{2}{*}{$\begin{array}{c}\begin{array}{l}\text { Standardized } \\
\text { Coefficients }\end{array} \\
\text { Beta }\end{array}$} & \multirow{2}{*}{$t$} & \multirow{2}{*}{$p$-value } \\
\hline & Beta & Std. Error & & & \\
\hline $\begin{array}{l}\text { Emotional } \\
\text { Intelligence }\end{array}$ & .194 & .060 & .200 & 3.210 & $.004^{* *}$ \\
\hline Spirituality & .318 & .236 & .090 & 2.345 & $.019^{*}$ \\
\hline Life Satisfaction & 2.593 & .349 & .490 & 7.429 & $.000^{* *}$ \\
\hline
\end{tabular}

${ }^{* *} p<.01,{ }^{*} p<.05$

Table 5 shows the corresponding regression coefficients that emotional intelligence $(\beta=.194, p=.004)$, spirituality $(\beta=.318, p=.019)$ and life satisfaction $(\beta=2.593, p=.000)$ significantly predicted self-actualization. With a result of the statistical relationship between self-actualization and emotional intelligence, spirituality and life satisfaction of the older adult respondents, it revealed a regression model in self actualization $=16.832+$ $\left(0.194 \mathrm{x}_{1}\right)+\left(0.318 \mathrm{x}_{2}\right)+\left(2.593 \mathrm{x}_{3}\right)$.

The said findings suggested that for older adults to achieve self actualization, they should possess a high level of emotional intelligence, a stronger sense of spirituality and better life satisfaction. The three predictors of the theory of Attaining Self-Actualization among Older Adults are thus validated.

\section{RECOMMENDATION}

1. Caring for older adults requires the element of utmost respect, treating them with dignity can motivate them to be emotionally intelligent and be more actualized;

2. Providing them immense opportunities to exercise their religion boosts their spirituality;

3. To achieve life satisfaction, the family and the community have the biggest responsibility to enhance their well-being;

4. The community, schools and interest groups should come up with better ways to provide avenues for the elderly to socialize, be 
productive and carry out their physical functions independently;

5. The national and local governments and the private sector can come come up with programs tailor-fitted to the self-actualization needs of older adults.

\section{REFERENCES CITED}

Bailey, T., Eng, W., Frisch, M., \& Snyder, C. R. (2007), Hope and optimism as related to life satisfaction. Journal of Positive Psychology, 2(3), 16869. Retrieved from https://goo.gl/BZqZJh, (accessed last 23 January 2016).

Bandura, A. (1999). Social cognitive theory: An agentic perspective. Asian Journal of Social Psychology, 2(1), 21-41. Retrieved from https://goo. gl/JGnw7t, (accessed last 18 January 2016).

Boyum, R. (2004). Characteristics of a self-actualizing person. Retrieved from https://goo.gl/m1UZJm, (accessed last 13 January 2016).

Bredle, J. M., Salsman, J. M., Debb, S. M., Arnold, B. J., \& Cella, D. (2011). Spiritual well-being as a component of health-related quality of life: the functional assessment of chronic illness therapy-spiritual well-being scale (FACIT-Sp). Religions, 2(1), 77-94. Retrieved from https://goo.gl/ srNcXf, (accessed last 11 January 2016).

Bulatao, J. (1989). Understanding the Filipino psyche. Manila, Philippines: La Salle University Press.

Cruz, G. (2004). Health transition among Filipino older people ( $3^{\text {rd }}$ ed.). Quezon City, Philippines: Grat Book Trading Publishing.

De Lazzari, S. A. (2000). Emotional intelligence, meaning, and psychological well (Doctoral dissertation, Trinity Western University). Retrieved from https://goo.gl/tnASPP, (accessed last 29 January 2016).

Diener, E., \& Fujita, F. (1995). Resources, personal strivings, and subjective well-being: a nomothetic and idiographic approach. Journal of personality and social psychology, 68(5), 926. 
Diener, E., Emmons, R.A., Larson, R.J., \& Griffin, S. (1985). The satisfaction with life scale. Journal of Personality Assessment, 49, 71-75. Retrieved from https://goo.gl/BW6Z3h, (accessed last 6 January 2016).

Diener, E., Suh, M., Lucas, E. \& Smith, H. (1999). Subjective well-being: Three decades of progress. Psychological Bulletin, 125(2), 276-302. Retrieved from https://goo.gl/E7d9b2, (accessed last 14 January 2016).

Greenberg, J. (1983). Overcoming egocentric bias in perceived fairness through self-awareness. Social Psychology Quarterly, 46( 2), 152-156.

Mroczek, D. \& Spiro, A. (2005). Change in life satisfaction during adulthood: Findings from the Veterans Affairs Normative Aging Study. Journal of Personality and Social Psychology, 88(1), 189-202. Retrieved from https://goo.gl/TKxHGJ, (accessed last 9 January 2016).

Pavot, W. \& Diener, E. (1993). Review of the Satisfaction With Life Scale. Psychological Assessment, 5(2), 64-172. Retrieved from https://goo.gl/ zBQB4j, (accessed last 3 January 2016).

Petrides, K. V. \& Furnham, A. (2006). The role of trait emotional intelligence in a gender-specific model of organizational variables. Journal of Applied Social Psychology, 36, 552-569. Retrieved from https://goo. gl/9Xz86f, (accessed last 14 January 2016).

Petrides, K. V. (2009). Psychometric properties of the trait emotional intelligence questionnaire (TEIQue). In Assessing emotional intelligence (pp. 85-101). Springer US. Retrieved from https://goo. gl/63j8nQ (accessed last 27 December 2015). 